\title{
O FAZER POLÍTICO DOS JOVENS DAS CLASSES POPULARES: AS OCUPACOES ESTUDANTIS PARANAENSES
}

\author{
THE POLITICAL MAKING OF YOUNG PEOPLE FROM POPULAR CLASSES: THE \\ STUDENT OCCUPATIONS OF PARANÁ STATE
EL HACER POLÍTICO DE LOS JÓVENES DE LAS CLASES POPULARES: LAS OCUPACIONES ESTUDANTILES PARANAENSES

Suely Aparecida Martins*

\begin{abstract}
REVISTA PEDAGÓGICA
Revista do Programa de Pós-graduação em Educação da Unochapecó | ISSN 1984-1566

Universidade Comunitária da Região de Chapecó | Chapecó-SC, Brasil Como referenciar este artigo: MARTINS, S. A. O fazer político dos jovens das classes populares: as ocupações estudantis paranaenses. Revista Pedagógica, Chapecó, v. 20, n. 43, p. 143-167, jan./abr. DOI: http://dx.doi.org/10.22196/rp.v20i43.4002
\end{abstract}

\begin{abstract}
RESUMO: Em um contexto de avanço das políticas neoliberais no Brasil e de acirramento da luta de classes, em 2016 alunos do Ensino Médio e superior paranaense ocuparam escolas e universidades. Este movimento ficou conhecido como Ocupa Paraná. As ocupações voltaramse contra a reforma do Ensino Médio e a PEC 241, mobilizando milhares de jovens. Nesse sentido, busca-se examinar em quemedida as experiências vivenciadas pelos alunos no contexto do Ocupa Paraná são indicativos do fazer político dos jovens das classes populares. Com base em E.P. Thompson e em relatos de estudantes, o artigo analisa a potencialidade formativa deste movimento para a formação política dos jovens das classes populares. Destaca-se a importância das ocupações na formação dos participantes, reveladora da constituição de um fazer político entre os jovens das classes populares em que transparecem o questionamento às formas políticas tradicionais e o desejo de uma participação política mais direta e horizontal.
\end{abstract}

Palavras-chave: Juventude. Ocupações dos estudantes. Movimento estudantil. Participação política.

ABSTRACT: At a time in which neo-liberal policies advance in Brazil and when there is an intensification of class struggle, in 2016 high school and university students from the state of Paraná, Brazil, occupied schools and university campuses. It became known as Movimento Ocupa Paraná. Its occupations turned against the reform of high school and a Proposed Constitutional Amendment (PEC 214), mobilizing thousands of young people. In this sense, the present paper seeks to examine to what extent the experiences lived by the students in the context of the Ocupa Paraná are indicative of the political making of the young people from popular classes. Based on E.P. Thompson and some reports of the students, this article analyzes the formative potentiality of the movement for the political formation of young people from popular classes. We highlight the importance of the occupations in the participants' formation, which is revealing of the constitution of a political making among popular class students where the questioning to traditional political forms and the desire of a more direct and horizontal political participation take place.

Keywords: Youth. Student occupations. Student movement. Political participation.

RESUMEN: En un contexto de avance de las políticas neoliberales en Brasil y del fortalecimiento de las luchas de clases, en 2016 alumnos de la enseñanza secundaria y superior del Estado del Paraná ocuparon escuelas y universidades. Este movimiento se quedó conocido por: Ocupa Paraná. Las ocupaciones se volvieron en contra a la reforma de la enseñanza secundaria y a la Propuesta de Emenda Constitucional 241, movilizando miles de jóvenes. En ese sentido, buscase examinar en qué medida las experiencias vividas por los alumnos en el contexto del Ocupa Paraná son indicativos de lo hacer político de los jóvenes de las clases populares. Con base en E.P. Thompson y en los relatos de estudiantes, el artículo analiza la potencialidad formativa de este movimiento para la formación política de los jóvenes de las clases populares. Destacase la importancia de las ocupaciones en la formación de los participantes, reveladora de la constitución de un hacer político entre los jóvenes de las clases populares en lo que se manifiestan las cuestiones a las formas políticas tradicionales y el anhelo a una participación política más directa y horizontal.

Palabras clave: Juventud. Ocupación de los estudiantes. Movimiento estudiantil. Participación política. 


\footnotetext{
* Doutora em Sociologia Política pela Universidade Federal de Santa Catarina (UFSC), docente do Curso de Pedagogia e do Programa de Pós-graduação em Educação (Mestrado) da Universidade Estadual do Oeste do Paraná, campus de Francisco Beltrão. Membro do Grupo de Pesquisa Sociedade Trabalho Educação na mesma instituição.
}

\section{INTRODUÇÃO}

No presente artigo, retomo preocupações que têm me acompanhado desde a graduação, ou seja, os processos de formação política da juventude, especificamente como as diversas instituições sociais contribuem para o "fazer" político dos jovens. Esta caminhada me permitiu o entendimento de que os processos de socialização política são mediatizados por instituições e agrupamentos dos quais os indivíduos fazem parte, bem como ocorrem a partir de condições histórico-sociais determinadas. Além disso, nos estudos realizados houve sempre a preocupação de se afastar de concepções com tendência a abstrair os sujeitos da história, neste caso, de desconsiderar os jovens com capacidade de agir socialmente.

Assim, a juventude, aqui, é entendida como uma categoria histórico-social, compreensão com a qual busco tecer considerações a respeito do movimento Ocupa Paraná, com o objetivo de levantar pistas sobre o potencial deste movimento, organizado pelos estudantes do Ensino Médio e também universitários, para a formação política dos jovens. Para tanto, faço uso da literatura sobre a história do Ensino Médio no Brasil e sobre a participação política da juventude para evidenciar que as ações políticas da juventude dizem respeito às lutas hegemônicas que se travam na sociedade de classes, abrindo possibilidades concretas de formação para os jovens. Analiso relatos de estudantes do município de Francisco Beltrão/PR, matérias veiculadas na imprensa no período das ocupações, as páginas no Facebook Ocupa Cema e Ocupa Beltrão, criadas pelos estudantes de Francisco Beltrão durante as ocupações. Examino ainda relatos de jovens que participaram das ocupações na região de Curitiba presentes no "Documentário Ocupa Tudo: Escolas Ocupadas no Paraná” (2016).

$\mathrm{O}$ artigo está organizado em três momentos: primeiramente, evidencia o dualismo estrutural que caracteriza o Ensino Médio no Brasil e que foi reforçado com a reforma do Ensino Médio, aprovada em 2017; em segundo lugar, procura entender as ocupações como parte de um contexto mais amplo, caracterizado pela crise econômica e política e também pelo acirramento da luta de classes, presentes nas diversas mobilizações que passam a acontecer seja no campo da direita, seja no campo da esquerda. Por fim, apresenta características presentes no movimento Ocupa Paraná, objetivando levantar pistas de seu potencial formativo, constituído a partir de experiências indicativas do fazer político dos jovens das classes populares.

\section{O ENSINO MÉDIO NO BRASIL}

A partir dos meados da década de 1990 o Brasil aumentou significativamente seus efetivos escolares. O Ensino Médio, por exemplo, passou de 3.772.698 matrículas em 
1991 para 8.376.852 em 2012, sendo considerado o nível de ensino que mais se expandiu no período (DAYRELL; JESUS, 2016). Todavia, esta expansão não erradicou problemas graves que acompanham esta etapa da escolarização, tais como a evasão e a repetência. De acordo com dados do Anuário Brasileiro da Educação Básica de 2016, no Brasil, no ano de 2014, 56,7\% dos jovens até 19 anos concluíram o Ensino Médio e, no estado do Paraná, 59,4\%. São dados que reforçam a existência de milhares de jovens brasileiros e paranaenses que ou não entraram nesta etapa de escolarização ou, se entraram, ficaram pelo caminho. De fato, em 2015 no Brasil eram 1.543.713 jovens entre 15 e 17 anos fora da escola, segundo levantamento do programa Todos pela Educação, com base no PNAD 2015.

Além da evasão e repetência, outra questão que chama a atenção em relação ao Ensino Médio brasileiro é o baixo aproveitamento dos alunos, o que coloca em xeque a qualidade da educação oferecida a eles. Dados do Índice de Desenvolvimento da Educação Básica (IDEB) divulgados em 2016 mostram que os alunos matriculados no Ensino Médio, em 2015, não alcançaram a meta que era de 4,3, mantendo o mesmo índice de 2011, ou seja, 3,7 (INEP, 2016). Vale acrescentar que foi essa uma das justificativas principais para a reforma do Ensino Médio encaminhada ao Congresso Nacional em 2016 pelo governo de Michel Temer e aprovada em 2017.

Todavia, o entendimento destas diversas questões que perpassam o Ensino Médio no Brasil apenas é possível a partir da compreensão de como esta etapa da escolarização se constituiu em uma sociedade extremamente desigual. A educação e a organização do sistema de ensino decorrem da estrutura de classes da sociedade capitalista e da correlação de forças que aí se estabelece; assim, a escola, ao responder às necessidades do mundo da produção, contribui para garantir a reprodução das desigualdades que caracterizam esta sociedade. Cabe à escola formar de acordo com a posição de cada classe na estrutura social, de modo a atender à divisão social e a técnica do trabalho, bem como formar em conformidade com a ideologia dominante (ALTHUSSER, 1992).

Kuenzer (1997) destaca que o Ensino Médio nacional tem sido caracterizado por uma dualidade estrutural. A autora explica que a história desta etapa de escolarização no Brasil é o resultado da tensão entre educação geral e educação específica, ou seja, entre uma educação de formação geral, propedêutica e uma educação específica, profissionalizante, técnica. Tal dualidade está expressa também na ambiguidade entre formar para o vestibular e formar para o mercado de trabalho. De maneira geral, retrata um sistema educacional que forma desigualmente as classes sociais e, ao fazê-lo, contribui para a formação humana unilateral, ou seja, aquela que historicamente tem contribuído para 
a cisão entre saber e fazer, constituindo um ser humano fragmentado, parcialmente desenvolvido em suas potencialidades.

A dualidade estrutural, característica do Ensino Médio brasileiro, pode ser evidenciada a partir das diversas leis que normatizaram sua oferta no decorrer da história. Pode-se citar aqui a reforma empreendida pelo ministro Gustavo Capanema em 1942, durante o governo Vargas e que instituiu as Leis Orgânicas do Ensino, estruturando o ensino propedêutico em primário e secundário, e o ensino técnico-profissional em industrial, comercial, normal e agrícola. Enquanto o ensino propedêutico visava à formação de jovens da elite para o ingresso no ensino superior, o ensino técnico-profissionalizante deveria apenas preparar para o mercado de trabalho, não dando acesso ao ensino superior. Esta reforma e aquelas preconizadas no âmbito de governos militares, de certa forma, respondiam à organização do capital com bases no taylorismo-fordismo. Já as mudanças ocorridas no Ensino Médio a partir da promulgação da Lei de Diretrizes e Bases da Educação Nacional (LDBEN no 9.394/1996), elas agora, sob a égide da acumulação flexível, trazem a marca das mudanças no mundo do trabalho, verificadas no Brasil, especialmente a partir dos anos de 1980. Formar para a vida tornou-se palavra de ordem, entendendo esta formação como necessária para "[...] desenvolver nas pessoas competências genéricas e flexíveis, de modo que elas pudessem se adaptar facilmente às incertezas do mundo contemporâneo" (CIAVATTA; RAMOS, 2011, p. 30), ou poderíamos afirmar: adaptar-se às incertezas do mundo do trabalho assalariado, agora sob a ideologia da empregabilidade.

Ao desvincular a educação profissional do Ensino Médio, o Decreto $n^{0}$ 2.208/97 reiterou a perspectiva de formação unilateral, que, sob a lógica economicista, coloca a educação a se mover a partir dos interesses imediatos do mercado de trabalho. Todavia, se em décadas passadas, na fase de prosperidade econômica e do pleno emprego, a escolarização, especialmente a etapa analisada no presente artigo, se colocava como o caminho para a profissionalização e a entrada no mercado de trabalho, constituindo a escola como promessa integradora (GENTILI, 2001), tal quadro começa a se alterar a partir da crise do capital na década de 1970, restando à escola formar para a empregabilidade. Neste caso, "[...] a qualificação e a requalificação profissional foram consideradas meios de acesso a setores ocupacionais, prevalecendo, para a maioria dos trabalhadores, a periferia da produção, esfera em que predomina tanto a lógica taylorista-fordista quanto a precarização do trabalho" (CIAVATTA; RAMOS, 2011, p. 30).

Durante o governo Lula, foi revogado o Decreto $n^{0} 2.208 / 1997$ e aprovado o Decreto $n^{0} 5.154 / 2004$ que instituiu o Ensino Médio integrado ao ensino técnico, tendo como base uma formação centrada no trabalho, na ciência e na cultura. $\mathrm{O}$ decreto respondia, ainda que 
minimamente, aos setores e educadores progressistas presentes no governo, que defendiam o Ensino Médio Integrado e Tecnológico, o qual, nos limites da sociedade burguesa, se colocaria como necessário para a formação dos filhos das classes trabalhadoras, bem como abriria brechas para a passagem à educação politécnica. Conforme Frigotto, Ciavatta e Ramos (2012, p. 45),

A possibilidade de integrar formação geral e formação técnica no Ensino Médio, visando a uma formação integral do ser humano, é, por essas determinações concretas, condição necessária para a travessia em direção ao Ensino Médio politécnico e à superação da dualidade de classes.

Porém, ainda que o decreto apontou para a superação da dualidade, ele também revelou a continuidade da fragmentação, já que abria a possibilidade de que a articulação entre educação profissional técnica de nível médio e o Ensino Médio fosse ofertada de maneira flexibilizada, sendo integrada, concomitante e subsequente. Ao permitir a flexibilização, o decreto manteve a possibilidade da separação entre educação geral e educação técnica e profissionalizante, posição que ficou clara na própria organização estrutural das secretarias de educação responsáveis por esta etapa de escolarização no interior do MEC naquele período, divididas em Secretaria de Educação Básica e Secretaria de Educação Profissional e Tecnológica, bem como na criação de diversos programas educativos direcionados à profissionalização, como o Programa Nacional de Acesso ao Ensino Técnico e Emprego (PRONATEC) em 2011, já no governo de Dilma Rousseff.

Conforme Ciavatta e Ramos (2011, p. 33), ainda que figurando mais no plano teórico do que prático, o governo Lula e, depois, o governo Dilma sinalizaram uma possibilidade de articulação entre Ensino Médio e profissionalizante em uma perspectiva de formação integral, evidenciando as lutas de classe presentes no interior do Estado burguês, mesmo quando a classe dominante é hegemônica tanto na sociedade civil como na sociedade política. Além disso, é importante considerar que foi durante estes governos que houve um aumento considerável da rede federal de Ensino Médio integrado, por meio dos Centros Federais de Educação Tecnológica (CEFETs) e da criação de institutos federais de educação.

Todavia tanto para o empresariado e o governo como para o senso comum da sociedade, o que prevalece é uma perspectiva pragmática e imediatista desta relação, ou seja, integrar o Ensino Médio e o ensino profissionalizante é preparar o jovem para o ingresso imediato ao mercado de trabalho diante da impossibilidade de continuidade de estudos em nível superior e, além disso, diante da suposição de torná-lo atrativo aos jovens, oferecendo-lhes uma profissão (CIAVATTA; RAMOS, 2011). Esta direção, aliás, foi 
reforçada com a reforma do Ensino Médio promovida pelo governo de Michel Temer.

Lima Filho (2017, p. 23) destaca que tal reforma somente pode ser compreendida dentro do quadro social e político em que foi produzida, ou seja, como "desdobramento do golpe midiático, parlamentar e institucional vivido no país em 2016" e como ataque frontal aos direitos sociais.

Em 2016, avançou no Congresso Nacional o pedido de impeachment da presidenta Dilma Rousseff, acusada de cometer crimes de responsabilidade fiscal. Acuada pela imprensa, pelo Congresso e por mobilizações patrocinadas por setores empresariais, foi afastada do cargo em 31 de agosto do mesmo ano. Vale acrescentar que o impeachment foi fortalecido pela bandeira anticorrupção que se instaurou no país, e que tem no Partido dos Trabalhadores o seu alvo predileto. A deposição de Dilma levou Michel Temer ao poder e, com ele, dava-se a largada para as reformas econômicas pretendidas pelas classes dominantes.

De fato, além do anúncio da Medida Provisória $\mathrm{n}^{\circ} 746 / 2016$, o presidente Temer também anunciou a PEC 241, propondo o congelamento dos gastos públicos por 20 anos, sob o discurso da necessidade de promover o ajuste fiscal necessário para que o país saísse da crise financeira. Posteriormente, também foram anunciadas a lei da terceirização e a reforma trabalhista, recentemente aprovadas, e da previdência, ainda em trâmite no Congresso.

A reforma do Ensino Médio, após aprovada pelo Congresso, foi sancionada em 16 de fevereiro de 2017, através da Lei $n^{0} 13.415$. Entre as principais mudanças introduzidas com ela estão: a ampliação da carga horária para 1.400 horas de maneira progressiva, até que a oferta desta etapa da escolarização se torne integral; a alteração curricular que, além da Base Nacional Comum, será composta por itinerários formativos, sendo linguagens e suas tecnologias; matemática e suas tecnologias; ciências da natureza e suas tecnologias; ciências humanas e sociais aplicadas; formação técnica e profissional. O arranjo curricular deverá ser constituído de modo que o estudante "escolha" o seu itinerário formativo, considerando-se a possibilidade de oferta dos sistemas de ensino. As disciplinas de Artes, Educação Física, Sociologia e Filosofia deixam de ter sua obrigatoriedade garantida, constituindo-se como conteúdos que devem ser trabalhados no Ensino Médio, o que implica que podem ser tratados em outras disciplinas.

Para Frigotto (2016) e Ramos (2017), entre outros autores, a reforma do Ensino Médio representa um retrocesso para a educação da classe trabalhadora, reforçando a dualidade estrutural já existente. Além disso, provoca o empobrecimento de conteúdo desta etapa do ensino. Frigotto (2016) afirma que esta reforma retrocede à década de 1990, quando o governo de Fernando Henrique Cardoso desvinculou a educação profissional do Ensino Médio. Segundo ele, 
Uma reforma que retrocede ao obscurantismo de autores como Desttut de Tracy que defendia, ao final do século XIX, ser da própria natureza e, portanto, independente da vontade dos homens, a existência de uma escola rica em conhecimento, cultura etc., para os que tinham tempo de estudar e se destinavam a dirigir no futuro e outra escola rápida, pragmática, para os que não tinham muito tempo para ficar na escola e se destinavam (por natureza) ao duro ofício do trabalho. (FRIGOTTO, 2016, [s. p.]).

Essa mesma perspectiva é compartilhada por Ramos (2017), que destaca que perde força a concepção de formação humana e integral dos sujeitos, que de certa forma encontrava-se presente nos documentos anteriores sobre o Ensino Médio. Passa a vigorar uma educação adequada aos interesses do mercado de trabalho. Neste caso, os jovens que escolherem como itinerário formativo a formação profissional serão duplamente prejudicados:

O jovem da classe trabalhadora que escolher este itinerário vai ter um Ensino Médio pela metade e a outra metade será uma instrumentalização para um trabalho simples, sem sequer a garantia de que sua força de trabalho será utilizada em um contexto econômico desfavorável. Ele perde no conteúdo e perde na finalidade da formação. (RAMOS, 2017, p. 7).

Além disso, ao propor a escolha de itinerários formativos, a reforma, sob o discurso de que os jovens não aguentam o excesso de disciplinas, esconde os reais problemas do Ensino Médio brasileiro que dizem respeito à falta de estrutura física e humana para o seu funcionamento com qualidade. São problemas que colocam em xeque a viabilidade das propostas anunciadas pela reforma, por exemplo, a ampliação da carga horária, bem como sinalizam que serão poucas as escolas públicas brasileiras a ter condições de ofertar todos os itinerários formativos. Tais problemas relacionam-se com o projeto educativo que tem sido reservado às classes populares em países que, como o Brasil, ocupam uma posição subalterna na divisão internacional do trabalho. Aqui, sob a concordância das classes dominantes, formam-se os jovens para o trabalho simples.

Embora a reforma do Ensino Médio tenha sido sancionada, não pode passar despercebido o fato de ter gerado, especialmente entre os jovens estudantes das escolas públicas brasileiras, um grande descontentamento, evidenciado logo que a Medida Provisória foi anunciada, tendo como consequência o movimento de ocupações de escolas públicas, iniciado em 3 de outubro de 2016, primeiramente no Paraná e, depois, estendido a outros estados. 


\section{O MOVIMENTO DE OCUPAÇÕES DE ESCOLAS PÚBLICAS NO PARANÁ}

As ocupações de escolas públicas no Paraná e no Brasil, em 2016, devem ser compreendidas associadas a outras manifestações estudantis ocorridas, especialmente a partir de 2013 e refletem um contexto econômico e político no país de acirramento dos conflitos de classe, que em parte, é revelado pelo questionamento e fazer político dos jovens estudantes.

Ao fazer um balanço histórico da educação no Brasil na primeira década do século XXI, período conjuntural em que esteve na presidência da República Luiz Inácio Lula da Silva, Frigotto (2010, p. 241) destaca que

[...] ao não disputar um projeto societário antagônico à modernização e ao capitalismo dependente e, portanto, à expansão do capital em nossa sociedade, centrando-se num projeto desenvolvimentista com foco no consumo e, ao estabelecer políticas e programas para a grande massa de desvalidos, harmonizando-as com os interesses da classe dominante, o governo não disputou um projeto educacional antagônico, no conteúdo, no método e na forma.

Prevaleceu a opção política de conciliação entre os interesses das classes dominantes com políticas de combate à desigualdade, sem, no entanto, afetar a ordem social capitalista. Conforme Grzybowski (2012, [s. p.]), optou-se por um desenvolvimento produtivista e consumista, mas com inclusão social:

Fizemos, sem dúvida, incríveis avanços sociais por meio de políticas ativas [...]. Mas isso também é forçoso reconhecer - fizemos sem mudar fundamentalmente a lógica do processo de desenvolvimento capitalista, sua estrutura social concentradora de ativos e sua base técnica industrial, produtivista e consumista, altamente predatória de recursos naturais, mercantilizando tudo, privatizando se necessário.

Já no primeiro governo de Dilma Rousseff, observam-se sinais de instabilidade: a queda no Produto Interno Bruto (PIB), o endividamento excessivo da população, a baixa produtividade e competitividade dos produtos brasileiros no plano internacional, entre outros, são problemas econômicos que vão se constituindo e que se somam à insatisfação da população com os serviços públicos e com certa descrença em relação aos políticos, alimentada por crescentes denúncias contra a corrupção. Tais questões se evidenciaram em junho de 2013 com manifestações de rua que aconteceram em diversas partes do país e que, 
inicialmente, foram motivadas pelos protestos do Movimento Passe Livre (MPL) em São Paulo, reprimidas com violência pela polícia. Conforme Scherer-Warren (2014, p. 419), “[...] o repúdio à repressão legitimada pelo Estado, por um lado, e a solidariedade à liberdade de expressão da cidadania, por outro, formaram o mote para a ampliação das manifestações em todo o país". Estas manifestações, por sua vez, assumiram uma pluralidade de reivindicações, com vozes dissonantes, que polarizavam interesses antagônicos e projetos políticos e partidários em disputa.

Interessa aqui registrar a presença dos jovens estudantes nestas manifestações, seja como movimento social organizado, no caso o MPL, seja de forma mais espontânea e não tão clara politicamente. Por sua vez, vale registrar que mesmo entre os jovens participantes, os posicionamentos políticos oscilavam entre tendências conservadoras ou elitistas e tendências mais progressistas, de modo a confirmar a presença de polos antagônicos nas manifestações:

[...] de um lado, os jovens do MPL defendendo políticas de sentido emancipatório e lutando por mudanças sistêmicas e político-culturais; de outro, alguns grupos de jovens se opondo a uma política pública (Mais Médicos) a favor de populações carentes, para defender o status quo e interesses corporativistas de classe. (SCHERER-WARREN, 2014, p. 419).

Esta constatação permite lembrar Mannheim (1968) quando afirma que a juventude não é essencialmente revolucionária, mas que pode assumir posições políticas tanto à esquerda quanto à direita. Da mesma forma, também são reveladores do conteúdo de classe presente nestas mobilizações e que se farão mais visíveis posteriormente na polarização político-ideológica que tomou conta do país.

Nesse sentido, concorda-se com Braga (2015) sobre a discordância de análises que apontam uma continuidade essencial entre as manifestações de 2013 e as manifestações de 2015, que levaram ao impeachment da presidenta Dilma Rousseff. O autor constrói seu argumento com base em dois elementos: a base social de protesto e sua direção política.

A base social, em 2013, era constituída majoritariamente por jovens trabalhadores das periferias e usuários dos transportes públicos que tomaram as ruas reagindo à violência da polícia contra os protestos organizados pelo MPL. Conforme Braga (2015), neste momento os setores médios tradicionais presentes corresponderam aproximadamente a $25 \%$ dos que participaram dos protestos. Já nas manifestações de 2015, houve o predomínio da participação de pessoas adultas na faixa etária entre 30 e 50 anos, a maioria branca e recebendo mais de cinco salários mínimos. Braga (2015, [s. p.], grifos do autor) destaca: "estamos diante de uma acentuada reviravolta social e não de uma anacrônica continuidade linear". 
Uma diferença também pode ser observada em relação ao conteúdo político destes dois momentos. Em 2013, embora a diversidade de reivindicações, entre elas aquelas ligadas a mudanças no sistema político, havia uma pauta popular centrada em mais investimentos públicos em transporte, saúde e educação (BRAGA, 2015). Já em 2015, desde o início as manifestações receberam atenção especial da mídia, contaram com apoio e financiamento de organizações com vínculos classistas, como a Federação das Indústrias do Estado de São Paulo (FIESP), e o foco foi o impeachment de Dilma. "Em suma, a ampla luta redistributivista subjacente a Junho com sua demanda por mais investimentos estatais chocando-se com os gastos com juros e amortizações da dívida pública foi substituída por ataques estreitos contra o Governo Federal" (BRAGA, 2015, [s. p.]).

Todavia, Braga (2015) não descarta uma relação entre as duas manifestações. Para ele, 2013 representa uma nova conjuntura política no país, marcada pela crise econômica, pelo fim da pacificação social e por uma nova era de conflito de classes, na qual os interesses tendem a se polarizar, como ficou demonstrado nas manifestações de 2015 e que levaram ao impedimento da presidenta em agosto de 2016. Destaca o autor:

[...].é urgente nos afastarmos do governismo para disputarmos os sentidos de Junho, reinventando uma esquerda à altura das tarefas impostas pelo atual ciclo de luta de classes. Para tanto, devemos fortalecer nossa análise estratégica e apostar em novas coalizões entre o sindicalismo rebelde e os movimentos sociais urbanos [...]. Para os que afirmam que as manifestações de 2013 prepararam a redução da maioridade penal em 2015, é necessário responder que Junho ainda pulsa no atual ciclo grevista, assim como na insurgência dos trabalhadores sem-teto. Os verdadeiros herdeiros de Junho são os trabalhadores precarizados e não a direita. (BRAGA, 2015, [s. p.]).

Ainda que restem dúvidas se de fato os herdeiros de junho são os trabalhadores precarizados, isto a história se encarregará de responder, ousamos afirmar, que "junho" continuou (e continua) a pulsar nos jovens estudantes das classes populares.

Em 2015 houve as ocupações das escolas públicas estaduais de São Paulo pelos estudantes contra a reorganização escolar, proposta pelo governador Geraldo Alkmin, que pretendia fechar 94 unidades escolares e efetuar o remanejamento de alunos de outras 754 (CORTI; CORROCHANO; SILVA, 2016). Entre dezembro e janeiro, foi a vez dos estudantes de Goiás ocuparem 27 escolas contra projeto que objetivava entregar parte da gestão das escolas, principalmente a contratação de professores e funcionários, a organizações sociais. Ocupações também ocorreram no Rio de 
Janeiro, Rio Grande do Sul, Ceará e em outros estados por motivos como solidariedade à greve de professores estaduais contra o controle ideológico nas escolas, por uma alimentação escolar saudável, entre outros temas (MORAES; XIMENES, 2016).

No Paraná, já no primeiro semestre de 2016, três escolas foram ocupadas em Maringá, tendo como pauta a merenda escolar. No segundo semestre, as ocupações se ampliaram no estado, agora com uma pauta nacional: a Medida Provisória $n^{0} 746 / 2016$, ou seja, contra a proposta de reformulação do Ensino Médio. Importa considerar que, em 2015, muitos estudantes, em apoio ao movimento grevista dos professores da rede estadual, vivenciaram a truculência do Estado e de seu aparato repressivo no dia 29 de abril, quando os professores tentaram ocupar a Assembleia Legislativa do Paraná (ALEP), onde naquele momento os deputados deveriam votar medidas que retiravam direitos dos trabalhadores da educação, sendo violentamente reprimidos. Observa-se que a motivação das ocupações, seja da ALEP, seja das escolas, estão em medidas adotadas pelos governos estadual e federal, de evidente caráter neoliberal e que significam um ataque à escola pública. São medidas que não apenas significam uma retirada de direitos, mas também reforçam o caráter de classe da educação no país, pois reiteram a desigualdade e a dualidade estrutural existente no sistema de ensino.

A primeira ocupação no Paraná ocorreu no Colégio Estadual Padre Arnaldo Jansen, localizado em um bairro periférico de São José dos Pinhais, região metropolitana de Curitiba, depois se estendendo a outros colégios da cidade e região, atingindo em dois dias cerca de 20 colégios ocupados e, rapidamente, se alastrando por todo o Paraná. Este estado foi aquele que mais registrou ocupações, chegando a 850 instituições de ensino ocupadas, conforme dados do Movimento Ocupa Paraná. Além do Paraná, outros 19 estados e o Distrito Federal registraram ocupações neste período, sendo mais expressivas em Minas Gerais, no Rio Grande do Sul, Goiás e Espírito Santo (TRUFFI, 2016).

As primeiras ocupações em Francisco Beltrão ocorreram em 11 de outubro de 2016, sendo o Colégio Léo Flach e Colégio Mario de Andrade os primeiros a serem ocupados. Dos 13 estabelecimentos de ensino que ofertam o Ensino Médio, dez foram ocupados pelos estudantes. Todavia, antes das ocupações no município, assim como ocorreu em outros lugares do Paraná, os estudantes se mobilizaram pelas redes sociais e organizaram outras formas de protestos, como a mobilização ocorrida em 10 de outubro de 2016 e que reuniu cerca de mil alunos de oito colégios estaduais de Francisco Beltrão:

$\mathrm{O}$ ato iniciou às 8 horas quando os estudantes segurando cartazes e faixas seguiram em 
caminhada até o calçadão central. Em seguida seguiram até o Núcleo Regional de Educação onde realizaram um ato. $\mathrm{O}$ manifesto que foi organizado através das redes sociais encerrou por volta das 10h30. (MACIEL, 2016, [s. p.]).

À luta contra a reforma do Ensino Médio somou-se a luta contra a PEC 241, que agregou ao movimento estudantes das universidades públicas estaduais e federais. No Paraná, várias universidades foram ocupadas. Em Francisco Beltrão, em 26 de outubro estudantes de geografia e pedagogia ocuparam um dos blocos da Universidade Estadual do Oeste do Paraná (UNIOESTE); na Universidade Tecnológica Federal do Paraná (UTFPR), pela manhã, alunos impediram a entrada de funcionários e professores, iniciando também um processo de ocupação.

A primeira reação do governador Beto Richa foi tentar associar o movimento dos estudantes com a esquerda política, acusando-os de estarem sendo manipulados e doutrinados. À medida que o movimento foi ganhando força, tentou alterar o discurso, prometendo que não aplicaria a reforma do Ensino Médio no estado sem antes promover um amplo debate. Depois, foi a vez do ministro da Educação Mendonça Filho ameaçar os estudantes com o cancelamento do Exame Nacional do Ensino Médio (ENEM) nas escolas ocupadas. Também coube ao ministro, por meio do MEC, solicitar aos institutos e universidades tecnológicas federais o nome dos estudantes participantes das ocupações. Seguindo o exemplo, o governo Beto Richa resolveu ameaçar funcionários, professores e diretores que demonstrassem algum envolvimento com as ocupações das escolas paranaenses. Em Francisco Beltrão, vários professores foram chamados a prestar depoimento na Ouvidoria do Estado, no Núcleo Regional de Educação, contra supostas denúncias de envolvimento.

A morte de um estudante durante a noite em uma das escolas ocupadas em Curitiba aumentou ainda mais as acusações contra o movimento, bem como fortaleceu pareceres favoráveis de juízes paranaenses em relação a pedidos de reintegração de posse solicitados pelo Estado.

As agitações no Paraná chegaram ao fim no início de novembro, depois de 36 dias de ocupação. Uma análise precipitada poderia levar à conclusão de que pouco adiantaram já que a reforma do Ensino Médio e a PEC 241 foram aprovadas. Todavia, deve-se perguntar: qual o significado deste movimento para "o fazer político" dos jovens estudantes? Tento levantar algumas pistas para esta questão a partir de relatos de jovens que participaram da ocupação em Francisco Beltrão, de algumas reportagens veiculadas no período, do acesso às páginas no Facebook do Ocupa Beltrão e Ocupa Cema (Colégio Estadual Mario de Andrade), criadas no período das ocupações e através do documentário Ocupa Tudo (2016). 


\section{O "FAZER-SE" POLÍTICO DOS JOVENS: A "EXPERIÊNCIA" DAS OCUPAÇÕES DAS ESCOLAS}

Utilizo as palavras "fazer-se" e "experiência" em uma referência às elaborações teóricas de Edward Palmer Thompson $(1981 ; 1998)$ e na tentativa de entender as ocupações dos estudantes como parte de um processo educativo e de formação humana que, ao mesmo tempo em que é reprodutor de valores e práticas presentes na sociedade de classes, pode também possibilitar a vivência de novos valores e práticas. Nesse sentido, parece que as ocupações no Paraná, produzidas em uma determinada materialidade histórica e social e não tomadas isoladamente, mas articuladas ao conjunto de ocupações de jovens das classes populares que vêm ocorrendo no Brasil e na América Latina, apresentam sinais históricos e contra-hegemônicos que não podem ser desconsiderados por aqueles que ainda acreditam nas possibilidades de mudanças sociais.

Thompson (1981) destaca a experiência como um processo de aprendizado que vai se constituindo no tempo e que se vincula à materialidade histórico-social e aos sujeitos nela inseridos. Neste sentido, existe a preocupação do autor em afastar-se de concepções que desconsideram o agir dos sujeitos na história, bem como daquelas que tomam a cultura como um elemento determinante da vida social. A experiência constitui-se como uma categoria de mediação que articula o ser social com a consciência social e que permite perceber a ação humana nos processos históricos,

[...] não como sujeitos autônomos, "indivíduos livres", mas como pessoas que experimentam suas situações e relações produtivas determinadas como necessidades e interesses e como antagonismos, e em seguida "tratam" essa experiência em sua consciência e sua cultura [...] e em seguida [...] agem, por sua vez, sobre sua situação determinada. (THOMPSON, 1981, p. 182).

Silva (2003, p. 108) destaca a importância do verbo tratar nesta definição de Thompson que, segundo ela, indica a "[...] reelaboração, ressignificação de sentimentos, maneiras de pensar, de ser e de agir a partir do mundo social em que se vive". É possível afirmar que se trata das experiências de homens e mulheres que articulam passado, presente e futuro, fenômenos econômicos, culturais e políticos. Elas acontecem em condições materiais e culturais determinadas, mas referem-se à experiência de sujeitos concretos que podem aceitá-la, recusá-la, modificá-la, ignorá-la. Neste sentido, concordo com a afirmação de Faria Filho (2008, p. 251), segundo a qual em Thompson "[...] é na e pela experiência que os sujeitos se constituem, sejam sujeitos indivíduos, sejam classes sociais". 
É a partir da categoria experiência que também se pode entender a compreensão que Thompson tem de classe social como um fenômeno histórico, resultado de relações entre os homens reais em contextos reais e constituída num longo processo de fazer-se (THOMPSON, 1998), processo de aprendizado, de conflitos e que articula ação humana e condicionamentos sociais.

A partir destes elementos, pretendo tecer algumas considerações sobre as ocupações ocorridas no Paraná e, em particular, no município de Francisco Beltrão em outubro de 2016.

Primeiramente, as ocupações dos estudantes paranaenses fazem parte de um processo histórico engendrado pela luta de classes no capitalismo brasileiro e que os jovens, no seu fazer político, em diferentes momentos, com menor ou maior consciência, têm evidenciado, especialmente nas lutas que travam em relação à educação. Já na década de 1960 isso fica evidente na atuação do movimento estudantil, constituído especialmente por jovens da classe média, inicialmente, que levantou a bandeira da educação pública e laica para depois ir se aproximando dos movimentos de esquerda e de suas lutas. Não é à toa que o movimento estudantil foi violentamente reprimido durante a ditadura militar. Nas décadas de 1980 e 1990, é a cultura um dos principais campos de atuação dos grupos de jovens contestadores que surgem (SOUSA, 2003). São grupos pastorais, raciais, de interesses e afinidades, em sua maioria formados por jovens das periferias urbanas que se utilizam da religião, da música, da dança etc. para constituírem formas de protesto social. São estes jovens das periferias que, a partir da década de 1990, começam a adentrar as escolas públicas brasileiras.

Souza (2003) chama a atenção também para os jovens atuantes no movimento estudantil secundarista ou universitário como grupos vinculados a partidos políticos de esquerda ou a grupos independentes. O primeiro grupo orienta-se pela linha programática do partido e busca manter o movimento estudantil como um campo de resistência à lógica do ensino atrelado pura e simplesmente aos interesses do mercado. Tais grupos procuram desenvolver formas de participação mais democráticas no movimento estudantil, afastando-se das práticas rígidas e hierárquicas tradicionais. Além de atuar no movimento estudantil, os grupos independentes fazem parte de coletivos de movimentos sociais que lutam em várias frentes, especialmente em relação à globalização capitalista; entre eles estão os que ficaram conhecidos como movimentos antiglobalização ou alterglobalização. São caracterizados por táticas políticas de ações diretas, pela recusa a vínculos partidários, pela defesa da organização horizontal e não hierárquica e por utilizarem os recursos da indústria cultural e tecnológica para manterem sua articulação e a adesão de militantes (SOUSA, 2003). Em relação ao fazer político dos jovens, estas características vão se firmando nas primeiras décadas 
do século XXI, estando presentes nos movimentos juvenis que eclodiram na Europa e na América do Norte, especialmente depois da crise financeira de 2008, e também na América do Sul e no Brasil.

Em relação à América do Sul, faço referência a um movimento específico pela relação com as ocupações estudantis no Brasil e que aconteceu em 2006: trata-se da chamada Revolta dos Pinguins, que mobilizou estudantes chilenos e que teve na ocupação de prédios escolares uma tática importante de ação. Inicialmente, as mobilizações no Chile apresentavam demandas específicas, como transporte gratuito para estudantes e gratuidade para exames de acesso à universidade. Tais demandas foram se ampliando, chegando à reforma educacional e ao questionamento do próprio sistema escolar, momento em que, além das ruas, os jovens estudantes chilenos passaram a ocupar as escolas. Em 2011, houve mais protestos, desta vez, os estudantes secundaristas se articularam com o movimento universitário. Entre 2010 e 2014, foi a vez dos estudantes argentinos utilizarem as ocupações das escolas como estratégia de luta (CORTI; CORROCHANO; SILVA, 2016). Em 2015 foram os estudantes paulistas que, inspirados nos estudantes chilenos, orientaram-se pela cartilha do Coletivo Mal Educado. A cartilha baseava-se na tradução de documento da Frente de Estudiantes Libertarios da Argentina, que apresentava as experiências das ocupações naquele país, também influenciadas pela luta dos secundaristas chilenos (JANUÁRIO et al., 2016). Em 2016 foi o Paraná o estado que, no decorrer de um mês, atingiu 850 escolas ocupadas. Mais uma vez a inspiração veio da Revolta dos Pinguins e da experiência de luta dos estudantes paulistas, como relatam estudantes paranaenses:

"A gente do Paraná se baseou nas ocupações de São Paulo no ano passado e nas ocupações do Chile". (Ana Júlia, estudante, Documentário Ocupa Tudo, 2016).

"Eu tinha ouvido falar da Revolta dos Pinguins e tinha visto as ocupações em São Paulo [...] e a gente viu que deu certo lá [...]. Então, a gente pensou e se todas as escolas começarem a ser ocupadas[...]. (Juliana, estudante, Documentário Ocupa Tudo, 2016).

No Paraná foi uma pauta federal - a reforma do Ensino Médio e depois a PEC 241 - a causa da mobilização dos jovens. Os jovens reclamaram que não foram ouvidos em relação à proposta, que era impositiva, carecendo de um amplo debate na sociedade, incluindo especialmente aqueles que seriam os mais atingidos: estudantes, professores e pais. Não foi à toa que, no ímpeto de conter as ocupações, os Núcleos Regionais de Educação organizaram um dia de debate sobre a reforma, que aconteceu em 13 de outubro de 2016. Na maioria dos núcleos do estado, incluindo o de Francisco Beltrão, a proposta foi rejeitada. Os resultados 
dos seminários e da pesquisa online realizada pela Secretaria da Educação foram apresentados ao ministro Mendonça Filho em 18 de outubro de 2016. Entretanto, em nota a Secretaria publicou que "[...] foi apresentado ao ministro o resultado das participações nos debates [...] que, de acordo com a Secretaria, geraram contribuições e proposta de aprimoramento à MP” (APP SINDICATO, 2016). Na página do Facebook de um dos colégios ocupados em Francisco Beltrão, lê-se:

Não queremos aprimorar essa medida, nós queremos que a MP seja desconsiderada em sua totalidade. Não queremos rebocar um reboco que nos impuseram. O Ensino Médio precisa sim de uma reforma, mas não através de uma MP. O assunto precisa ser amplamente debatido com professores, alunos, especialistas na área e todos os demais interessados. E não vamos desistir do movimento apenas porque "o Ensino Médio se tornou pauta", continuaremos ocupando cada vez mais porque parece que nossos governantes e representantes da educação ainda não entenderam. (OCUPA CEMA, 2016, [s. p.]).

A não possibilidade de participação efetiva em uma questão que afetaria diretamente os jovens se constitui como um dos motes para a indignação, revolta e organização dos estudantes. Mais do que votar para eleger presidentes, governadores, prefeitos, senadores, deputados, vereadores e diretores das escolas, o recado dos estudantes é que eles desejam uma participação política mais efetiva, mais democrática, indicando um processo em curso, no mundo e no Brasil, em que os jovens vêm questionando a hierarquia e as formas tradicionais das relações políticas, especialmente aquelas expressas na democracia representativa (SOUSA, 2014). Vale destacar que, assim como chamou a atenção Januário et al. (2016) em relação às ocupações paulistas, a crítica dos estudantes paranaenses ficou materializada na própria forma como organizaram o movimento das ocupações: pela prática democrática por meio de assembleias. O autor afirma que os alunos paulistas utilizaram a cartilha organizada pelo Coletivo Mal Educado, que trazia, por exemplo, sugestões de como organizar assembleias:

Os estudantes aderiram à ideia, pondo em discussão coletiva desde a organização mais "prática" do dia a dia, tais como as equipes de limpeza e "segurança", até decisões a respeito dos rumos da ocupação e da articulação externa com outras escolas. Além disso, o manual recomenda a organização de atividades (recreativas ou formativas) a serem feitas durante o dia, envolvendo não só a participação de alunos, como também dos professores, pais e todos aqueles que apoiam a ocupação. (JANUÁRIO et al., 2016, p. 12). 
A partir de relatos de estudantes, reportagens e das visitas feitas às escolas durante as ocupações em Francisco Beltrão, é possível inferir elementos organizativos muitos próximos aos mencionados por Januário et al. (2016) e que também são indicativos da prática democrática presente no movimento. Isso aparece, por exemplo, no relato de estudantes:

"Tudo o que a gente fazia era por assembleia e você vê que no dia a dia não tem isso, de você discutir com todo mundo o que vai ser decidido. Lá não, lá era a gente pela gente e a gente discutindo. A gente vendo o que queria, e aí a gente começou a colocar em discussão o Projeto Escola Sem Partido". (Ana Julia, estudante, Documentário Ocupa Tudo, 2016).

"Nós tivemos uma organização horizontal. Nós não precisamos de líder nenhum. Nós não tivemos ninguém que sempre estivesse a frente. Ou era todo mundo ou não era ninguém”. (Willian, estudante, Documentário Ocupa Tudo, 2016).

"Não existia um superior. Apenas escolhíamos alguém para falar representando os demais". (Estudante de Francisco Beltrão, 2016). "As decisões que envolviam o coletivo eram colocadas em votação e pensando no bem comum, vencia a qual fosse mais votada". (Estudante de Francisco Beltrão, 2016).

É importante mencionar que o movimento sempre se autodenominou apartidário, sem, no entanto, desconsiderar a importância de apoio externo:

"Acho muito importante essa horizontalidade do Movimento que está acontecendo agora, mas também acho muito importante que todas as entidades ajudem, sem tomar a frente, mas que apoiem os estudantes, estejam todos juntos, unidos". (Estudante, Documentário Ocupa Tudo, 2016).

Em parte, este apoio veio de pais, professores e entidades que colaboraram com o movimento por meio da doação de mantimentos, de solidariedade em momentos de tensão e conflitos e com a partilha de conhecimentos. Assim como em outras escolas ocupadas do Paraná, em Francisco Beltrão, entre as atividades realizadas nas escolas estava a realização de palestras e debates, ou nos dizeres dos próprios participantes: "rodas de conversa". Tais atividades procuravam conhecer e aprofundar temas considerados relevantes, sendo que a própria Medida Provisória e a PEC foram pontos de debates e que se estenderam à comunidade escolar, como se observa em convite feito por alunos ocupados do Colégio Estadual Suplicy: "Aproveitamos este para convidar toda a comunidade escolar para uma palestra e debate onde debateremos a PEC 241, a MP 746 e as ocupações nas escolas que ocorrerá domingo as 
19:3oh [sic] no Colégio Suplicy. Sua presença é muito importante!" (OCUPA CEMA, 2016, [s. p.]). A estas atividades somavam-se à realização de atividades culturais, como apresentações musicais, saraus de poesia, oficinas de hip-hop, e outras. Importa registrar que a realização de tais atividades, organizadas pelos estudantes e que envolviam participantes da comunidade dispostos a colaborar com o movimento, são indicativos de que os jovens, ao mesmo tempo em que atribuem importância ao conhecimento utilizar o tempo das ocupações nas escolas para palestras e debates é significativo em relação a isso -, parecem acenar também para uma crítica a escola e a permanência nela de formas tradicionais de ensino, bem como apontam para a necessidade de a escola reconhecer a cultura como elemento fundamental de socialização e sociabilidade juvenil.

Nas escolas, os estudantes adotaram escalas e divisão de tarefas. Conforme reportagem da revista Carta Capital (TRUFFI, 2016, [s. p.]): "Todos reproduzem um sistema parecido. Os ocupantes dividem-se em comissões de comunicação, segurança e cozinha, entre outras. Cada qual fica responsável por atividade de uma área”. Também um estudante de Francisco Beltrão afirmou: "Todos os envolvidos no movimento auxiliavam em todas as tarefas, como limpeza, refeições, organização da instituição [...]”.

Estas questões indicativas de uma prática democrática nas ocupações são reveladoras de processos de aprendizados que, embora não se resumam apenas às experiências nas ocupações, têm nestas um momento fundamental para o fazer político dos jovens das classes populares à medida que 1) os coloca em um coletivo: "porque a gente questionava as paradas e de repente a gente se uniu por uma causa maior"; "Caramba a gente não está sozinho, têm muitos estudantes junto com a gente[...]" (Estudantes, Documentário Ocupa Tudo, 2016); 2) como sujeitos do processo: "Conseguimos mobilizar as pessoas[...]"; "Autonomia e autogestão, é nós por nós defendendo a educação" (Documentário Ocupa Tudo, 2016); e 3) em situação de conflito: conflito com o Estado e com seus aparatos repressivos, com parte da comunidade escolar, incluindo alunos, pais e professores contrários ao movimento.

Por parte do Estado veio a não disposição para o diálogo, a repressão e a violência, além de propagandas oficiais na tentativa de conquistar a opinião pública, inclusive os jovens, em relação à reforma do Ensino Médio. A propaganda apelou para a possibilidade de "escolha" do jovem no tocante ao seu percurso formativo, incluindo a possibilidade de ensino técnico. Omitiu-se que as escolhas são feitas a partir de condições materiais determinadas e que a reforma do Ensino Médio representa um retrocesso ao reforçar a separação entre saber e fazer e negar aos jovens das classes populares o acesso a uma formação integral e humana. Em contrapartida, a resistência dos jovens em relação à MP denunciava as condições precárias das escolas; as dificuldades de conciliar trabalho e estudo e, portanto, 
na inviabilidade de uma proposta de escola de tempo integral; a crítica à proposta de ensino técnico:

"Não pensaram no povo, na infraestrutura da escola... Como praticar um ensino integral se não há espaço, salas de aula, professores $e$ os alunos que trabalham para ajudar em casa??? Para que e para quem foi feita a PEC? A favor da classe trabalhadora é que não foi!!!" (Estudante, Francisco Beltrão, 2016).

"Quer reformar o Ensino Médio? Começa reformando a escola que está muito mais precária do que o Ensino Médio". (Sabrina, estudante, Documentário Ocupa Tudo, 2016).

"Ensino Técnico para o meio de produção, não! Querem transformar a gente em uma máquina". (Mariana, estudante, Documentário Ocupa Tudo, 2016).

São condições vividas pelos jovens e que remetem à materialidade social em que se encontram inseridos e que dizem respeito às condições concretas nas quais se realizam o processo educacional e a condição social de parte considerável de estudantes das escolas públicas: estudante e trabalhador.

De parte da comunidade escolar vieram ataques de que se tratava de um movimento baderneiro, irresponsável, de que os estudantes estavam sendo manipulados, que depredavam as escolas e que estariam prejudicando os que queriam estudar. Tais ataques, reforçados na imprensa, revelam o predomínio de uma representação negativa e preconceituosa em relação aos jovens, que tende a considerá-los na perspectiva "da falta, da incompletude, da irresponsabilidade, da desconfiança” (DAYRELL, 2007, p. 1117) e não como sujeitos com capacidade de agir politicamente e intervir socialmente. A ocupação das escolas pelos estudantes mostrou a capacidade deles de ação e organização e a vontade de tomar a política com as próprias mãos, de se fazer ouvir, de participar das decisões.

Em resposta aos que atacavam o movimento, eles, em sua maioria, tentavam responder com sua organização e atitudes que demonstravam o cuidado com a escola e um senso de coletivo, de preocupação com o outro. Conforme se lê na página do Facebook do Ocupa Cema (2016, [s. p.]): "Nossa ocupação é pacífica e repudiamos qualquer forma de desordem e depredação do patrimônio público. Estamos fazendo a limpeza do colégio graças a conscientização do movimento estudantil". Em contraposição aos pais e estudantes que reivindicavam o direito de estudar, de concluir o terceiro ano do Ensino Médio e fazer o Enem, os estudantes participantes das ocupações, muitos também no último ano do Ensino Médio, argumentavam que estavam lutando por seus irmãos, pela garantia de um futuro melhor para as crianças e pela melhoria da educação pública no país.

É importante destacar, ainda, que muitos dos jovens que participaram das ocupações relataram que aprenderam 
a respeitar as diferentes opiniões e a conviver melhor com quem não tinha uma boa relação; que houve uma mudança individual a partir do fim das ocupações; relataram uma maior responsabilidade, um amadurecimento e outra visão de mundo. A fala de uma estudante que participou da ocupação de uma universidade em Francisco Beltrão sintetiza tais questões:

"Posso dizer que o movimento me proporcionou uma rica formação política, não só com relação aos assuntos reivindicados, mas também no envolvimento e respeito ao outro. Entramos no movimento com um pensamento, e saímos dele com um outro olhar para diversas questões, ou seja, o movimento nos fez refletir e rever conceitos, aprimorar ideias, foi nos construindo". (Estudante Francisco Beltrão).

Portanto, observa-se a importância da participação no movimento para os estudantes. A experiência das ocupações proporcionou aos jovens, ainda que de maneira incipiente, uma crítica ao sistema de ensino e às formas tradicionais de relações políticas, conduzidas, na maioria das vezes, de baixo para cima, sem a participação efetiva dos sujeitos. Mais do que a crítica à reforma do Ensino Médio, os estudantes levantaram sua voz contra a estrutura precária da educação brasileira e, ao fazê-lo, tentaram produzir práticas mais democráticas e autônomas, ainda que imperfeitas. Para muitos deles, o aprendizado vivido pode ser desencadeador de outras experiências formativas abrindo possibilidades concretas de formação política.

\section{CONSIDERAÇÕES FINAIS}

Os jovens vêm mostrando uma disposição para o agir político, como pode ser visto nas diversas mobilizações que ocorrem pelo Brasil e pelo mundo a partir de 2010. São mobilizações que têm questionado o capitalismo e que, no Brasil, se remetem à perda de direitos ou, ainda, ao seu uso precário, como no caso da educação reservada às classes populares. A fala de uma estudante universitária é relevante:

"É preciso ter muita coragem para lutar contra todo um sistema, organizado e cheio de artimanhas para derrubar nossas ideias. Acredito que a formação política de todos que lutaram e defenderam seus ideais durante as ocupações irá render bons frutos. Nada está acabado. Como diz um colega meu: 'O movimento não acabou, ainda temos muito por que lutar". (Estudante, Francisco Beltrão).

"Ainda temos muito por que lutar". Talvez seja este um dos aprendizados mais importantes para muitos dos 
estudantes que participaram das ocupações, pois indica a compreensão da importância do agir político na sociedade em que vivemos e, em um momento em que as políticas neoliberais e a perda de direitos avançam assustadoramente, este reconhecimento é salutar, uma vez que revela a disposição para o agir político.

Por fim, são relevantes as ocupações na formação dos estudantes participantes, bem como é reveladora a constituição de um fazer político entre os jovens das classes populares, em que transparece o questionamento das formas políticas tradicionais e o desejo de uma participação mais direta e horizontal. É fazer político que tem se constituído em um contexto social de acirramento da luta de classes. Cabe questionar se esta experiência dos estudantes se somará a outras, podendo, de fato, se constituir como parte de um processo autoformativo mais abrangente.

\section{REFERÊNCIAS}

ALTHUSSER, Louis. Aparelhos ideológicos de Estado. 6. ed. Rio de Janeiro: Graal, 1992.

ANUÁRIO BRASILEIRO DA EDUCAÇÃO BÁSICA. 2016. Disponível em: <http://www.todospelaeducacao.org. br/biblioteca/1545/anuario-brasileiro-da-educacao-basica-2016/>. Acesso em: 15 mar. 2017.

APP SINDICATO. Governo não relata ao MEC a verdadeira posição do Paraná sobre a reforma do Ensino Médio. APP: 16 de out. de 2016. Disponível em: $<$ http://appsindicato.org.br/governo-nao-relata-ao-mec-a-verdadeira-posicao-do-parana-sobre-a-reforma-do-ensino-medio/\#.WAbAnbcBwuE.facebook>. Acesso em: 22 jul. 2017.

BRAGA, Ruy. Os sentidos de junho. Blog da Boitempo. Disponível em: <https://blogdaboitempo.com. $\mathrm{br} / 2015 / 07 / 06 / o s-s e n t i d o s-d e-j u n h o /$ ?blogsub=confir ming\#blog_subscription-5>. Acesso em: 8 maio 2017.

BRASIL. Lei $\mathrm{n}^{0}$ 13.415, de 16 de fevereiro de 2017. Disponível em: < http://www.planalto.gov.br/ccivil_o3/_ ato2015-2018/2017/lei/l13415.htm>. Acesso em: 22 jul. 2017.

BRASIL. Medida Provisório $\mathrm{n}^{0}$ 746, de 22 de setembro de 2016. Disponível em: < http://www.camara.gov.br/proposicoesWeb/prop_mostrarintegra? codteor $=1494234>$. Acesso em: 22 jul. 2017.

CATINI, Carolina de Roig; MELLO, Gustavo Moura de. Escolas de luta, educação política. Educação e sociedade, Campinas, v. 37, n. 137, p. 1177-2202, out./dez. 2016. 
CIAVATTA, Maria; RAMOS, Marise. Ensino médio e educação profissional no Brasil: dualidade e fragmentação. Retratos da Escola, Brasília, v. 5, n. 8, p. 27-41, jan./jun. 2011. Disponível em: <http//www.esforce.org.br > Acesso em: 10 de abr. de 2017.

CORTI, Ana Paula de O.; CORROCHANO, Maria Clara; SILVA, José Alves da. "Ocupar e resistir": a insurreição dos estudantes paulistas. Educação e sociedade, Campinas, v. 37, n. 137, p. 1159-1176, out./dez. 2016.

DAYRELL, Juarez. A escola "faz" as juventudes? Reflexões em torno da socialização juvenil. Educação e Sociedade, Campinas, v. 28, n. 100, Especial, p. 1105-1128, out. 2007. Disponível em: <http://www.cedes.unicamp.br>. Acesso em: 10 nov. 2016.

DAYRELL, Juarez; JESUS, Rodrigo Ednilson. Juventude, ensino médio e os processos de exclusão escolar. Educação e Sociedade, Campinas, v. 37 , n. 135, p. 407-423, abr./jun. 2016.

DOCUMENTÁRIO OCUPA TUDO: Escolas ocupadas no Paraná (2016): documentário dirigido por Carlos Pronzato. Disponível em: <https://www.youtube.com/ watch?v=JLz7szvKOFw> . Acesso em: 6 maio 2017.

FARIA FILHO, Luciano Mendes de. Fazer história da educação com E.P. Thompson: trajetórias de um aprendizado. In: FARIA FILHO, Luciano Mendes de. (org.). Pensadores sociais e história da educação. 2. ed. Belo Horizonte: Autêntica, 2008. p. 247-264.

FRIGOTTO, Gaudêncio. Os circuitos da história e o balanço da educação no Brasil na primeira década do século XXI. Revista Brasileira de Educação, Rio de Janeiro, v. 16, n. 48, p. 235-274, jan./abr. 2011.

FRIGOTTO, Gaudêncio. Reforma de ensino médio do (des) governo de turno: decreta-se uma escola para os ricos e outra para os pobres. Boletim da Anped, 22 de set. 2016. Disponível em: <http://www.anped.org.br/news/ reforma-de-ensino-medio-do-des-governo-de-turno-decreta-se-uma-escola-para-os-ricos-e-outra>. Acesso em: 11 jul. 2017.

FRIGOTTO, Gaudêncio; CIAVATTA, Maria; RAMOS, Marise. A gênese do Decreto n. 5154/2004: um debate no contexto controverso da democracia restrita. In.: FRIGOTTO, Gaudêncio; CIAVATTA, Maria; RAMOS, Marise (orgs.). Ensino médio integrado: concepções e contradições. 3 . ed. São Paulo: Cortez, 2012. p. 21-56

GENTILI, Pablo. Educar para o desemprego: a desintegração da promessa integradora. In.: FRIGOTTO, Gaudêncio 
(org.). Educação e crise do trabalho: perspectivas de final de século. 5. ed. Petrópolis, RJ: Vozes, 2001.

GOHN, Maria da Glória. Sociologia dos movimentos sociais. São Paulo: Cortez, 2013.

GRZYBOWSKI, Cândido. Brasil: como criar o salto para a "grande transição". Carta Maior, 01/12/2012. Disponível em: <http://www.cartamaior.com.br/?/Editoria/Politica/ Brasil-como-criar-as-condicoes-para-a-\%2527Grande-Transicao\%2527-\%250D\%250A/4/26169>. Acesso em: 13 jul. 2017.

INEP - Brasil. Dados do Ideb 2015 já estão disponíveis para consulta. Brasília: Inep, 8 de set. 2016. Disponível em: <http://portal.inep.gov.br/artigo/-/ asset_publisher/B4AQV9zFY7Bv/content/dados-do-ideb-2015-ja-estao-disponiveis-para-consulta/21206>. Acesso em: 8 maio 2017.

JANUÁRIO, Adriano et al. As ocupações de escolas em São Paulo (2015): autoritarismo burocrático, participação democrática e novas formas de luta social. Fevereiro, São Paulo, v. 9, abr. 2016. Disponível em: <http://www.revistafevereiro.com/pdf/9/12.pdf>. Acesso em: 27 jul. 2017.

KUENZER, Acácia. Ensino médio e profissional: as políticas do Estado neoliberal. São Paulo: Cortez, 1997.

LIMA FILHO, Domingos Leite. É necessário resistir ao empobrecimento do currículo. Entrevista concedida a Cátia Guimarães, Poli: saúde, educação, trabalho, Rio de Janeiro, v. 9, n. 50, p. 23-26, mar./abr.2017.

MACIEL, Solange. Estudantes realizam manifestação contra reforma do Ensino Médio. PPNews, Francisco Beltrão, 10 de out. 2016. Disponível em: <http://ppnewsfb.com.br/notici a/15436/estudantes-realizam-manifestao-contra-reforma-do-ensino-mdio >. Acesso em: 13 jul. 2017.

MANNHEIM, Karl. O problema da juventude na sociedade moderna. In.: BRITTO, Sulamita (org.). Sociologia da juventude. Rio de Janeiro, Zahar, 1968 (v. 2). p. 69-94.

MARGULIS, M.; URRESTI, M. La juventud es más que una palabra. In.: MARGULIS, M (Org.). La juventud es más que una palabra. Buenos Aires: Biblos, 1996. p. 13-30.

MORAES, Carmen Sylvia V. M; XIMENES, Salomão Barros. Políticas educacionais e resistência estudantil. Educação e Sociedade, Campinas, v. 37, n. 137, out./dez. 2016.

NÚCLEO REGIONAL DE EDUCAÇÃO - FRANCISCO BELTRÃO. Em assembleia, alunos decidem manter 
ocupações em Francisco Beltrão. NRE Francisco Beltrão: 25 de out. 2016. Disponível em: <http://www. nre.seed.pr.gov.br/modules/noticias/article.php?storyi $\mathrm{d}=10030>$. Acesso em: 22 jul. 2017.

NÚCLEO REGIONAL DE EDUCAÇÃO - FRANCISCO BELTRÃO. NRE de Francisco Beltrão discute proposta de reforma do ensino médio. NRE Francisco Beltrão: 14 out. 2016. Disponível em: <http:// www.nre.seed.pr.gov.br/modules/noticias/article.php?s toryid=9933 $>$. Acesso em: 22 jul. 2017.

OCUPA BELTRÃO. Disponível em: <https://www.facebook.com/Ocupa-Beltr\%C3\%A30-1704545496531151/>. Acesso em: 22 jul. 2017.

OCUPA CEMA. Disponível em: <https://pt-br.facebook. com/OCUPACEMA/> . Acesso em: 22 jul. 2017.

PEREIRA JUNIOR, José Nilton Alves; MOREIRA, Eugenio Eduardo P. Formação integral e dualidade estrutural na política de educação profissional no Governo Lula: Decreto n. 5154/04, Educação em Debate, Fortaleza, a. 35-38, n. 66-71, p. 172-183, 2013/2016. Disponível em: <http://www. periodicosfaced.ufc.br/index.php/educacaoemdebate/ar ticle/view/80/43. Acesso em: 10 maio 2017.

RAMOS, Marise. Entrevista: MÉDIOTEC: nova cara do PRONATEC para acelerar Reforma do Ensino Médio. Poli: saúde, educação, trabalho, Rio de Janeiro, v. 9, n. 50, p. 6-7, mar./abr.2017.

SCHERER-WARREN, Ilse. Manifestações de rua no Brasil 2013: encontros e desencontros na política. Caderno CRH, Salvador, v. 27, n. 71, p. 417-429, mai./ago 2014.

SILVA, M. A. M. Assentamento Bela Vista, a peleja para ficar na terra. In: MARTINS, J. de S. (Coord.). Travessias: a vivência da reforma agrária nos assentamentos. Porto Alegre: Ed. da UFRGS, 2003. p. 107-157.

SOUSA, Janice Tireli Ponte de. A experiência contemporânea da política entre jovens do sul do Brasil. Buenos Aires: CLACSO, 2014.

SOUSA, Janice Tireli Ponte de. As insurgências juvenis e as novas narrativas políticas contra o instituído. Cadernos de Pesquisa, Florianópolis, n. 32, fev. 2003.

THOMPSON, E. P. A miséria da teoria ou um planetário de erros. Rio de Janeiro: Zahar, 1981.

THOMPSON, E. P. As peculiaridades dos ingleses. In.: NEGRO, A. L.; SILVA, S. (Orgs.). E. P. Thompson: as peculiaridades dos ingleses e outros artigos. 3. ed. 
167 O FAZER POLÍTICO DOS JOVENS DAS CLASSES POPULARES: AS OCUPAÇÕES ESTUDANTIS PARANAENSES

Campinas: Ed. da UNICAMP, 1998. n. 10 (Coleção Textos Didáticos). $1 \mathrm{v}$.

TRUFFI, Renan. Sob pressão da justiça, secundaristas completam um mês de ocupações nas escolas. Carta Capital, São Paulo, 4 de nov. de 2016. Disponível em: <https:// www.cartacapital.com.br/politica/sob-pressao-da-justica-estudantes-secundaristas-completam-um-mes-de-ocupacoes-nas-escolas>. Acesso em: 20 nov. 2016.

Recebido em: 30/09/2017 Aprovado em: 22/02/2018 Publicado em: 30/04/2018 